\title{
The prevalence of and risk factors for diabetes mellitus and impaired glucose tolerance among Tibetans in China: a cross- sectional study
}

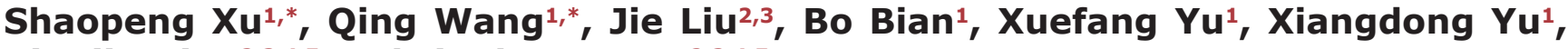 \\ Xianjia Ning ${ }^{2,3,4,5}$ and Jinghua Wang $2,3,4,5$ \\ ${ }^{1}$ Department of Cardiology, Tianjin Medical University General Hospital, Tianjin 300052, China \\ ${ }^{2}$ Department of Neurology, Tianjin Medical University General Hospital, Tianjin 300052, China \\ ${ }^{3}$ Department of Epidemiology, Tianjin Neurological Institute \& Tianjin Medical University General Hospital, Tianjin 300052, China \\ ${ }^{4}$ Tianjin Neurological Institute, Key Laboratory of Post-Neuroinjury Neuro-repair and Regeneration in Central Nervous \\ System, Ministry of Education and Tianjin City, Tianjin 300052, China \\ ${ }^{5}$ Central of Clinical Epidemiology, Tianjin Medical University General Hospital, Tianjin 300052, China \\ "These authors contributed equally to this work \\ Correspondence to: Jinghua Wang, email: jhw8799@yahoo.com \\ Xianjia Ning, email: xjn0906@gmail.com
}

Keywords: diabetes mellitus, epidemiology, prevalence, risk factors, Tibetans

Received: June 24, 2017 Accepted: August 28, $2017 \quad$ Published: September 28, 2017

Copyright: $\mathrm{Xu}$ et al. This is an open-access article distributed under the terms of the Creative Commons Attribution License 3.0 (CC BY

3.0), which permits unrestricted use, distribution, and reproduction in any medium, provided the original author and source are credited.

\section{ABSTRACT}

The prevalence of diabetes mellitus (DM) and impaired glucose tolerance (IGT) has increased worldwide, although their prevalence and determinants among Tibetans are currently unknown. We thus aimed to explore the prevalence of and risk factors for DM and IGT among Tibetans in China. In 2011, 1659 Tibetan adults (aged $\geq$ 18 years) from Changdu, China, were recruited to this cross-sectional study. They completed a questionnaire and underwent physical examinations and laboratory testing to assess risk factors for DM and IGT. The age-standardized prevalence of DM and IGT among Tibetans was $6.2 \%$ and $19.7 \%$, respectively. A higher annual family income, alcohol consumption, and higher fasting plasma glucose (FPG) level were risk factors for DM, with odds ratio (ORs) and $95 \%$ confidence intervals (CIs) of 3.48 (1.43-8.48; $P=0.006)$ for those with family incomes of $>1600$ USD/year, 3.06 (1.31-7.17; $P=0.010)$ for alcohol consumption, and $13.99(7.76-25.22 ; P<0.001)$ for FPG level. However, altitude was found to be negatively associated with the risk of DM; compared to individuals living at $<3500$ meters, the risk of DM decreased by $65 \%$ for those living at 3500-3999 meters $(P=0.034)$ and by $89 \%$ for those living at $\geq 4000$ meters $(P=\mathbf{0 . 0 1 5})$. Age, FPG levels, and low-density lipoprotein cholesterol levels were significantly associated with IGT among Tibetans aged $\geq 18$ years. These findings suggest that the prevalence of DM in Tibetans may continue to increase in future decades following rapid economic development, and it is crucial to address the management of conventional risk factors for reducing the disease burden of DM among Tibetans.

\section{INTRODUCTION}

DM has become one of the most important public health issues in the world [1]. The global age-standardized DM prevalence increased from $4.3 \%$ in 1980 to $9.0 \%$ in
2014 in men and from $5.0 \%$ to $7.9 \%$ in women [2]. The number of adults with DM worldwide increased from 108 million in 1980 to 422 million in 2014 [2]. Additionally, the burden of DM, in terms of both prevalence and the number of adults with DM, increased at a greater rate in 
low-income and middle-income countries than in highincome countries [2]. The worldwide cost of DM was 1.31 trillion USD, or $1.8 \%$ of the global gross domestic product (GDP), in 2015 [3].

A recent study estimated that the prevalence of DM was $11.1-12.3 \%$ in middle-income countries and that the prevalence varied across different countries [4]. Half of adults with DM in 2014 lived in five countries: China, India, the USA, Brazil, and Indonesia [2]. Moreover, the prevalence of DM has increased rapidly in China, with a considerable subsequent burden [5]. The prevalence of DM was 2.6\% in 2002, and it reached $9.7 \%$ in 2012 according to the Report on the Status of Nutrition and Chronic Diseases of Chinese residents [6]. A recent study among Tibetans in China reported that the prevalence of DM was $2.9 \%$ [2].

However, these studies were conducted in a population residing at the same altitude. Additionally, these studies reached conclusions based on a small population living at base levels and excluded lamas, and some laboratory testing items were not included in these studies. Thus, the prevalence of and risk factors for DM among Tibetans residing at different altitudes, including lamas, are currently unknown.

We thus performed a population-based survey among Tibetans living in China that included lamas and Tibetans living at different altitudes. We aimed to assess the prevalence of and risk factors for DM in Tibet, China.

\section{RESULTS}

\section{Descriptive characteristics of participants}

A total of 1960 residents completed the study survey and examinations, for a response rate of $90.1 \%$. Of those, 1659 Tibetans were included in the present study, after excluding 134 residents without complete demographic data and 167 residents of other ethnicities. Of these, there were $822(49.5 \%)$ men and $837(50.5 \%)$ women. The mean age was 44 years overall, 41.45 years in men and 46.51 years in women; $53 \%$ of participants were under 45 years old. The education levels were low both in men and in women, with a $60 \%$ illiteracy rate overall. Among all participants, $56.9 \%$ had an family income of $<800$ USD/ year; $59.5 \%$ of participants were farmers or herdsmen; and $56 \%$ of individuals lived in rural or pastoral areas (Table 1).

\section{Associations of DM and IGT with conventional risk factors in the univariate analysis}

The age-standardized prevalences of DM and IGT were $6.2 \%$ and $19.7 \%$ overall, $7.9 \%$ and $17.4 \%$ in men, $4.9 \%$ and $18.8 \%$ in women, respectively; there was a significantly higher prevalence of DM in men than in women $(P=0.012)$. The DM prevalence increased significantly with increasing age, education level, and annual family income; however, the opposite trends were observed for education level and altitude. Moreover, the age-standardized prevalence of DM was more likely to be high in those with hypertension, obesity, dyslipidemia, and/or alcohol consumers. The prevalence of IGT significantly increased with age (Table 2). Moreover, the age-standardized prevalences of DM and IGT were associated with the levels of BMI, TC, TG, HDL-C, and FPG (Table 3).

\section{Risk factors associated with DM and IGT among Tibetans aged $\geq 18$ years in the multivariate analysis}

Table 4 shows that annual family income, altitude, alcohol consumption, and FPG levels were significantly associated with DM among Tibetans aged $\geq 18$ years. A higher annual family income, alcohol consumption, and higher FPG levels were the risk factors for DM, with ORs (95\% CIs) of $3.48(1.43-8.48 ; P=0.006)$ for those with a family income of $>1600$ USD/year, 3.06 (1.31-7.17; $P=0.010)$ for those who consumed alcohol, and 13.99 (7.76-25.22; $P<0.001)$ for higher FPG levels. However, altitude was found to be negatively associated with the risk of DM; compared to individuals living at $<3500$ meters, the risk of DM decreased by $65 \%$ for those living at 3500 3999 meters $(P=0.034)$ and by $89 \%$ for living at $\geq 4000$ meters $(P=0.015)$.

Age and the levels of FPG and LDL-C were independent risk factors for IGT among Tibetans aged $\geq 18$ years. Compared to individuals aged 18-34 years, the risk of IGT increased by $95 \%$ for those in the 35-44 years group, by $86 \%$ for those aged $45-54$ years, by 1.02 -fold for those aged 55-64 years, and by 1.54-fold for those aged 65 years and older (all $P<0.05$ ). The corresponding ORs $(95 \%$ CIs) were $1.41(1.04-1.91 ; P=0.025)$ for LDL-C, and $3.38(2.69-4.23 ; P<0.001)$ for FPG, respectively (Table 5).

\section{DISCUSSION}

This is the first study to report the prevalence of and risk factors for DM and IGT among Tibetans in China. The age-standardized prevalences of DM and IGT were $6.2 \%$ and $19.7 \%$ overall, respectively. Family income, altitude, alcohol consumption, and FPG levels were factors that were associated with DM among Tibetans aged $\geq 18$ years. There was an increased risk of DM in residents with a higher family income ( $>1600 \mathrm{USD} /$ year compared to $<800$ USD/year), those who were alcohol drinkers, and those who had elevated levels of FPG. However, the risk of DM decreased with an increase in altitude; compared to residents living at $<3500$ miles, the risk of DM decreased by $65 \%$ and $89 \%$ in those living at 3500-3999 meters and $\geq 4000$ meters, respectively. Moreover, older age and high levels of LDL-C and FPG were independent risk factors for IGT. 
Table 1: The demographic characteristics of participants in Tibetans

\begin{tabular}{|c|c|c|c|}
\hline Characteristics & $\operatorname{Men}(n=822)$ & Women $(n=837)$ & Total $(n=1659)$ \\
\hline Age, years, means (SD) & $41.45(15.01)$ & $46.51(15.05)$ & $44.00(15.24)$ \\
\hline \multicolumn{4}{|l|}{ Age group, years, n (\%): } \\
\hline $18-34$ & $299(36.38)$ & $194(23.18)$ & $493(29.72)$ \\
\hline $35-44$ & $194(23.60)$ & $193(23.06)$ & $387(23.33)$ \\
\hline $45-54$ & $161(19.59)$ & $201(24.01)$ & $362(21.82)$ \\
\hline $55-64$ & $105(12.77)$ & $138(16.49)$ & $243(14.65)$ \\
\hline$\geq 65$ & $63(7.66)$ & $111(13.26)$ & $174(10.48)$ \\
\hline \multicolumn{4}{|l|}{ Education, years, n (\%): } \\
\hline 0 & $394(47.93)$ & $607(72.52)$ & $1001(60.34)$ \\
\hline $1-6$ & $330(40.15)$ & $102(12.19)$ & $432(26.04)$ \\
\hline $7-9$ & $46(5.60)$ & $43(5.14)$ & $89(5.36)$ \\
\hline $10-12$ & $26(3.16)$ & $38(4.54)$ & $64(3.86)$ \\
\hline$>12$ & $26(3.16)$ & $47(5.61)$ & $73(4.40)$ \\
\hline \multicolumn{4}{|c|}{ Family income yearly, USD: } \\
\hline$<800$ & $508(61.80)$ & $436(52.09)$ & $944(56.90)$ \\
\hline $800-1599$ & $145(17.64)$ & $162(19.36)$ & $307(18.51)$ \\
\hline$>1600$ & $169(20.56)$ & $239(28.55)$ & $408(24.59)$ \\
\hline \multicolumn{4}{|l|}{ Occupation, n (\%): } \\
\hline Officer & $56(6.81)$ & $93(11.11)$ & $149(8.98)$ \\
\hline Workers & $26(3.16)$ & $15(1.79)$ & $41(2.47)$ \\
\hline Farmers & $334(40.63)$ & $582(69.53)$ & $916(55.21)$ \\
\hline Herdsman & $31(3.77)$ & $40(4.78)$ & $71(4.28)$ \\
\hline Shaman & $337(41.00)$ & $7(0.84)$ & $344(20.74)$ \\
\hline Others & $38(4.63)$ & $100(11.95)$ & $138(8.32)$ \\
\hline \multicolumn{4}{|l|}{ Altitude, meter, n (\%): } \\
\hline$<3500$ & $444(54.0)$ & $463(55.3)$ & 907 (54.7) \\
\hline $3500-3999$ & $266(32.4)$ & 334 (39.9) & $600(36.2)$ \\
\hline$\geq 4000$ & $112(13.6)$ & $40(4.8)$ & $152(9.1)$ \\
\hline \multicolumn{4}{|l|}{ Residence, n (\%): } \\
\hline Urban & $144(17.52)$ & $251(29.98)$ & $395(23.81)$ \\
\hline Rural & $322(39.17)$ & $539(64.40)$ & $861(51.90)$ \\
\hline Pastoral area & $31(3.77)$ & $44(5.26)$ & $75(4.52)$ \\
\hline Temple & $325(39.5)$ & $3(0.36)$ & $328(19.77)$ \\
\hline
\end{tabular}

In 2014, the prevalence of DM was reported to be $9.0 \%$ for men and $7.9 \%$ for women worldwide [2]. The reported prevalence of DM in China has an extensive range. A national survey revealed that the prevalences of DM and IGT among adults aged 20 years and older in 2010 were $9.7 \%$ (10.6\% for men and $8.8 \%$ for women) and $15.5 \%$ (16.1\% for men and $14.9 \%$ for women), respectively [7]. The findings from a nationally representative cross-sectional survey on the ethnic variation of DM and IGT prevalence in China indicated that the overall standardized prevalence of diabetes in Chinese adults was estimated at $10.9 \%(95 \% \mathrm{CI}$,
$10.4-11.5 \%)$ in 2013 , or $10.2 \%(95 \% \mathrm{CI}, 9.7-10.7 \%)$ for women and $11.7 \%(95 \% \mathrm{CI}, 10.9-12.4 \%)$ for men; the estimated prevalence of IGT was $35.7 \%$ (95\% CI, $34.1-37.4 \%)$ for the overall population, or $35.0 \%(95 \%$ CI, 33.4-36.7\%) for women and 36.4\% (95\% CI, $34.6-$ $38.2 \%$ ) for men; Tibetan and Muslim Chinese individuals had a significantly lower prevalence of diabetes than did Han participants [8]. The overall age-standardized prevalence of type 2 diabetes, combining urban and rural areas, was $12.6 \%$ in 2009 among Chinese adults aged 3574 years in Shanghai [9], which was considerably higher than that in a previous report [7]. However, a relatively 
Table 2: The association of DM and IGT with related factors among Tibetans aged $\geq 18$ years in univariate analysis

\begin{tabular}{|c|c|c|c|c|}
\hline \multirow[t]{2}{*}{ Demographical features } & \multicolumn{2}{|c|}{ DM } & \multicolumn{2}{|c|}{ IGT } \\
\hline & Rate $(95 \% \mathrm{CI})$ & $P$ & Rate $(95 \% \mathrm{CI})$ & $P$ \\
\hline Gender: & & 0.012 & & 0.199 \\
\hline Men & $7.9(6.0-9.8)$ & & $17.4(14.7-20.0)$ & \\
\hline Women & $4.9(3.4-6.3)$ & & $19.7(17.7-21.7)$ & \\
\hline Total & $6.2(5.0-7.4)$ & & $18.8(16.0-21.4)$ & \\
\hline Age group, years: & & $<0.001$ & & $<0.001$ \\
\hline $18-34$ & $1.9(0-3.9)$ & & $9.8(7.1-12.5)$ & \\
\hline $35-44$ & $4.8(2.6-6.9)$ & & $21.5(17.3-25.6)$ & \\
\hline $45-54$ & $8.0(5.2-10.8)$ & & $32.0(27.1-36.9)$ & \\
\hline $55-64$ & $13.3(9.0-17.7)$ & & $24.5(18.9-30.0)$ & \\
\hline$\geq 65$ & $13.3(6.9-19.6)$ & & $27.7(20.9-34.5)$ & \\
\hline Education level, years: & & $<0.001$ & & 0.704 \\
\hline 0 & $5.2(3.8-6.7)$ & & $15.8(15.5-20.1)$ & \\
\hline $1-6$ & $7.3(4.7-9.8)$ & & $17.5(13.8-21.1)$ & \\
\hline$\geq 7$ & $11.9(7.6-16.2)$ & & $16.1(11.2-20.9)$ & \\
\hline Family income yearly: & & $<0.001$ & & 0.450 \\
\hline$<800$ & $3.9(2.7-5.2)$ & & $17.7(15.2-20.2)$ & \\
\hline $800-1599$ & $5.3(2.8-7.9)$ & & $16.1(12.0-20.3)$ & \\
\hline$\geq 1600$ & $13.1(9.8-16.4)$ & & $19.9(16.0-23.8)$ & \\
\hline Altitude, meter: & & 0.050 & & 0.333 \\
\hline$<3500$ & $7.0(5.3-8.7)$ & & $16.7(14.1-18.8)$ & \\
\hline $3500-3999$ & $5.3(3.5-7.1)$ & & $21.0(17.7-24.3)$ & \\
\hline$\geq 4000$ & $3.2(0.4-6.0)$ & & $15.8(10.0-21.6)$ & \\
\hline Residence: & & 0.001 & & 0.379 \\
\hline Urban & $9.5(6.6-12.4)$ & & $14.8(11.2-18.3)$ & \\
\hline Rural/Pastoral area & $5.2(3.8-6.7)$ & & $19.9(17.3-22.5)$ & \\
\hline Temple & $3.8(1.7-6.0)$ & & $16.7(12.6-20.8)$ & \\
\hline Hypertension: & & 0.002 & & 0.244 \\
\hline Yes & $7.2(5.6-8.7)$ & & $19.3(17.2-22.0)$ & \\
\hline No & $3.1(1.7-4.5)$ & & $16.6(13.5-19.7)$ & \\
\hline Obesity: & & 0.001 & & 0.130 \\
\hline Yes & $10.7(7.0-14.4)$ & & $22.5(17.6-27.5)$ & \\
\hline No & $5.0(4.9-7.3)$ & & $17.8(13.3-22.3)$ & \\
\hline Dyslipidemia: & & $<0.001$ & & 0.186 \\
\hline Yes & $9.1(6.9-11.3)$ & & $19.6(16.7-22.6)$ & \\
\hline No & $3.3(2.2-4.5)$ & & $16.7(14.3-19.2)$ & \\
\hline Smoking: & & 0.895 & & 0.496 \\
\hline Yes & $7.2(2.0-12.5)$ & & $15.0(7.8-22.3)$ & \\
\hline No & $6.0(4.8-7.2)$ & & $18.2(16.2-20.2)$ & \\
\hline Alcohol consumption: & & 0.004 & & 0.182 \\
\hline Yes & $12.2(7.0-17.3)$ & & $22.7(16.1-29.3)$ & \\
\hline No & $5.5(4.3-6.6)$ & & $17.6(15.6-19.6)$ & \\
\hline
\end{tabular}


Table 3: The association of DM and IGT with the measurements among Tibetans aged $\geq 18$ years in univariate analysis

\begin{tabular}{|c|c|c|c|c|}
\hline \multirow[t]{2}{*}{ Disease History } & \multicolumn{2}{|c|}{ DM } & \multicolumn{2}{|c|}{ IGT } \\
\hline & means (SD) & $P$ & means (SD) & $P$ \\
\hline BMI: & & $<0.001$ & & 0.001 \\
\hline Yes & $26.53(4.43)$ & & $24.56(4.03)$ & \\
\hline No & $23.75(3.85)$ & & $23.75(3.85)$ & \\
\hline TC: & & $<0.001$ & & 0.018 \\
\hline Yes & $5.54(1.27)$ & & $4.94(1.16)$ & \\
\hline No & $4.53(1.03)$ & & $4.53(1.03)$ & \\
\hline TG: & & $<0.001$ & & 0.011 \\
\hline Yes & $2.17(2.94)$ & & $1.14(0.92)$ & \\
\hline No & $1.01(0.78)$ & & $1.01(0.78)$ & \\
\hline HDL-C: & & 0.550 & & 0.410 \\
\hline Yes & $1.50(0.48)$ & & $1.55(0.44)$ & \\
\hline No & $1.52(0.44)$ & & $1.52(0.44)$ & \\
\hline LDL-C: & & $<0.001$ & & $<0.001$ \\
\hline Yes & $2.79(0.97)$ & & $2.61(0.91)$ & \\
\hline No & $2.29(0.76)$ & & $2.29(0.76)$ & \\
\hline FPG: & & $<0.001$ & & $<0.001$ \\
\hline Yes & $8.01(4.34)$ & & $5.44(0.84)$ & \\
\hline No & $4.86(0.67)$ & & $4.86(0.67)$ & \\
\hline
\end{tabular}

lower prevalence of DM was found in other regions, such as in Hunan (1.5\%), Guizhou (1.9\%), Guangxi (2.5\%), and Hubei (2.7\%) [10]. Consistent with these results, the agestandardized prevalences of DM and IGT were $6.2 \%$ and $18.8 \%$ overall, $7.9 \%$ and $17.4 \%$ for men, $4.9 \%$ and $19.7 \%$ for women among Tibetans aged $\geq 18$ years in China, respectively. The specific lifestyle in this population may explain the lower prevalence of DM.

Age has previously been found to be associated with a higher prevalence of DM [11]. However, in this study, age was associated with the risk of IGT but not with DM. An increasingly sedentary lifestyle with increasing age could contribute to the age-related increases in the prevalence of IGT. The exact mechanisms of the age difference between DM and IGT prevalence would need to explore deeply.

It has been reported that, compared to residents at sea level, residents living at high altitudes have lower fasting glucose levels [12-16] and better glucose tolerance [17]. A recent study from the United States revealed that the risk of DM among adults living at high altitudes (1500-3500 meters) decreased by $12 \%$ compared to that for those living at $<500$ meters, after adjusting for age, sex, BMI, ethnicity, and lifestyle-related factors [18]. In this study, the prevalence of DM decreased as altitude increased. The exact mechanisms underlying the lower prevalence of DM at high altitudes are unclear. In order to improve adaptation to hypoxic conditions, glucose oxidation and glycolysis replace fatty acid oxidation; this may contribute to the lower risk of DM in residents living at higher altitudes [19]. A previous study reported a highfrequency missense mutation in the EGLN1 gene, which encodes prolyl hydroxylase 2 (PHD2), among Tibetans, which prevents the development of polycythemia in these high-altitude dwellers [20] and that was unrelated to any increased hemoglobin oxygen affinity or any hemoglobin variants for these adaptive changes [21]. Another PPARA haplotype that encodes the nuclear peroxisome proliferators activated receptor $\alpha$ (which regulates fatty acid metabolism and in turn hypoxia-inducible factors) is correlated with a possible decrease in the activity of fatty acid oxidation [22]. These data suggest that highaltitude adaptations may offer protection from DM at high altitudes but that the risk of DM would increase at lower altitudes [23].

The association between alcohol drinking and the risk of DM has been established. Previous studies showed that alcohol consumption exhibits a U-shaped relationship with the risk of T2DM in both men and women, with two alcoholic drinks per day ( $\sim 50 \mathrm{~g} /$ day $)$ increasing the relative risk of DM [24, 25]. Moderate alcohol intake (1-3 drinks/ day) was inversely related to T2DM risk in adults [26]. Alcohol consumption was found to protect against DM at a level of $24 \mathrm{~g} /$ day for women and $22 \mathrm{~g} /$ day for men but it became a risk factor at levels of $>50 \mathrm{~g} /$ day for women and $>60 \mathrm{~g} /$ day for men [25]. Severe alcohol consumption 
Table 4: Associated risk factors of DM among Tibetans aged $\geq 18$ years in the multivariate analysis

\begin{tabular}{|c|c|c|c|}
\hline Risk factors & Reference & OR & $95 \% \mathrm{CI}$ \\
\hline Men & Women & 1.32 & $0.66 \sim 2.64$ \\
\hline Age: & 18-34 years & & \\
\hline $35-44$ years & & 0.79 & $0.27 \sim 2.31$ \\
\hline $45-54$ years & & 0.62 & $0.21 \sim 1.85$ \\
\hline $55-64$ years & & 1.06 & $1.35 \sim 3.24$ \\
\hline$\geq 65$ years & & 2.17 & $0.68 \sim 6.90$ \\
\hline Education level & 0 Years & & \\
\hline 1-6 Years & & 0.68 & $0.28 \sim 1.65$ \\
\hline$\geq 7$ Years & & 0.53 & $0.18 \sim 1.57$ \\
\hline Family income yearly & $<800$ USD & & \\
\hline 800-1599 USD & & 1.65 & $0.62 \sim 4.35$ \\
\hline > 1600 USD & & 3.48 & $1.43 \sim 8.48$ \\
\hline Altitude: & $<3500$ meters & & \\
\hline 3500-3999 meter & & 0.35 & $0.14 \sim 0.93$ \\
\hline$\geq 4000$ meter & & 0.11 & $0.02 \sim 0.66$ \\
\hline Residence & Urban & & \\
\hline Rural/ Pastoral area & & 1.17 & $0.42 \sim 3.27$ \\
\hline Temple & & 0.95 & $0.21 \sim 4.32$ \\
\hline Hypertension & No & 0.58 & $0.25 \sim 1.34$ \\
\hline Obesity & No & 0.83 & $0.27 \sim 2.59$ \\
\hline Dyslipidemia & No & 1.02 & $0.44 \sim 2.39$ \\
\hline Alcohol consumption & No & 3.06 & $1.31 \sim 7.17$ \\
\hline BMI & - & 1.12 & $0.98 \sim 1.28$ \\
\hline $\mathrm{TC}$ & - & 0.77 & $0.41 \sim 1.45$ \\
\hline TG & - & 1.23 & $0.89 \sim 1.70$ \\
\hline LDL-C & - & 1.99 & $0.92 \sim 4.30$ \\
\hline FPG & - & 13.99 & 7.76 25.22 \\
\hline
\end{tabular}

was associated with elevated FPG in adults aged 16 to 43 years [27]. Similar to those studies, alcohol consumption was found to be an independent risk factor for DM in this study, after adjustment for other conventional risk factors; the risk of DM in alcohol drinkers increased by more than two-fold compared to that for non-drinkers. However, the dose-reaction relation between alcohol consumption and the risk of DM was not assessed in this study.

The association of the LDL-C level and the presence of IGT has been undetermined. Several studies have demonstrated that the prevalence of IGT was not associated with the level of LDL-C [28, 29], but hypertriglyceridemia emerged as a significant risk factor for DM and IGT in an Asian population [30]. In contrast to these previous studies, the level of LDL-C in plasma, not the TG level, was significantly associated with the risk of IGT among Tibetans aged $\geq 18$ years in China in this study. These findings imply that there was potential combined effect between risk factors.
There were several limitations to this study. First, it was a cross-sectional study; thus, it cannot determine causal conclusions. Second, the population was selected in one area; however, the four-stage randomly stratified cluster sampling method was used to make the study population representative. Third, all participants were from higher altitudes ( $>3200$ meters), and we did not include a population at a lower altitude for purposes of comparison. However, the subgroup analyses were stratified according to altitude ( $<3500$ meters, 3500-3999 meters, and $\geq 4000$ meters). Fourth, the prevalence of DM was associated with annual family income, but as Tibet is an undeveloped region, the level of economic development in this population was low overall. Thus, although the level of income in Tibetans is relatively low, annual family income was stratified into three groups ( $<800 \mathrm{USD} /$ year, 800-1600 USD/year, and $\geq 1600 \mathrm{USD}$ /year). Moreover, the dose-reaction relation between alcohol consumption and the risk of DM was not assessed in this study, which may have affected the 
Table 5: Associated risk factors of IGT among Tibetans aged $\geq 18$ years in the multivariate analysis

\begin{tabular}{cccc}
\hline Risk factors & Reference & OR & $\mathbf{9 5 \% C I}$ \\
\hline Age: & $18-34$ years & & \\
35-44 years & & $\mathbf{1 . 9 5}$ & $\mathbf{1 . 2 8} \mathbf{2 . 9 7}$ \\
$45-54$ years & & $\mathbf{1 . 8 6}$ & $\mathbf{1 . 2 0} \mathbf{2 . 8 7}$ \\
$55-64$ years & & $\mathbf{2 . 0 2}$ & $\mathbf{1 . 2 6} \mathbf{3 . 2 4}$ \\
$\geq 65$ years & - & $\mathbf{2 . 5 4}$ & $\mathbf{1 . 5 3} \mathbf{4 . 2 1}$ \\
BMI & - & 1.01 & $0.97 \sim 1.05$ \\
TC & - & 0.98 & $0.76 \sim 1.26$ \\
TG & - & 1.09 & $0.91 \sim 1.30$ \\
LDL-C & - & $\mathbf{1 . 4 1}$ & $\mathbf{1 . 0 4} \mathbf{1 . 9 1}$ \\
FPG & $-\mathbf{3 . 3 8}$ & $\mathbf{2 . 6 9 \sim 4 . 2 3}$ \\
\hline
\end{tabular}

evaluation of the association of alcohol drinking with DM. Finally, this study was conducted in 2011; thus, there is a 6-year interval, so the information it provides on the prevalence of DM and IGT is not up-to-date. Thus, it is necessary to perform a more current study of the trends for risk factors among this population.

This is the first study to report the prevalence of and risk factors for DM and IGT among Tibetans in China. A higher prevalence of IGT was observed among residents living in rural or pastoral areas, although there was a lower prevalence of IGT overall. China is a developing country undergoing a transition from an agricultural society to an industrial society. The Tibet Autonomous Region is the least urbanized area in China, and the level of economic development in this population is lower overall. According to our study, the prevalence of DM in Tibetans may increase as the economy develops. A low altitude and elevated FPG levels were common risk factors for DM and IGT among Tibetans aged $\geq 18$ years. However, a higher family income and alcohol drinking increased the risk of DM; older age and elevated levels of LDL-C were independent risk factors for IGT. These findings suggest that the prevalence of DM in Tibetans may continue to increase in future decades following rapid economic development, and it is crucial to address the management of conventional risk factors in order to reduce the disease burden of DM among Tibetans.

\section{MATERIALS AND METHODS}

\section{Study population}

The study design has been described previously [31]. In brief, the study population was recruited from the Changdu region of the Tibet Autonomous Region of China from September 2010 to June 2011. There are 11 counties, including 142 townships and 11 central temples, in the Changdu region, with altitudes ranging from 3200 to 4500 meters. More than $95 \%$ of residents are Tibetan.
A four-stage randomly stratified cluster sampling method was used to select a representative sample of the Tibetan population in China. First, all 11 counties in the Changdu region were stratified into three groups according to altitude: $<3500$ meters, $3500-4000$ meters, and $>4000$ meters. Second, one county was selected from each altitude group, which included three counties. Third, four townships from each selected county were selected, for a total of 12 townships. Fourth, three villages or neighborhoods from each selected township were selected, resulting in a total of 36 villages or neighborhoods. Moreover, one central temple was selected in each county; all qualified lamas were recruited in the present study. Finally, all residents aged $\geq$ 18 years from the selected 31 villages, 5 neighborhoods, and 3 central temples were recruited in this survey.

The ethics committee of Changdu Region People's Hospital, Tibet approved the study, and written informed consent was obtained from all participants during recruitment.

\section{Study content}

In 2011, 1659 Tibetan adults aged $\geq 18$ years from Changdu, China were recruited to this cross-sectional study. The questionnaire, physical examinations, and laboratory testing were completed, and the prevalence of DM and risk factors, including hypertension, obesity, dyslipidemia, and current smoking, were evaluated. The association between the DM risk factors and demographic characteristics, as well as geographic altitude, was assessed.

Detailed information evaluated included demographic information, such as sex, age group (1834 years, 35-44 years, 45-54 years, 55-64 years, $\geq 65$ years), education level ( 0 years, $1-6$ years, $\geq 7$ years), and occupation (officer, workers, farmers, herdsman, lama, others); socioeconomic status, including yearly family income (< 800 USD/year, 800-1599 USD/year, $1600 \mathrm{USD} /$ year); geographic characteristics, including altitude ( $<3500$ meters, 3500-3999 meters, and $\geq 4000$ meters), and residence (township, rural, temple); and 
lifestyle factors, including cigarette smoking (no, yes) and alcohol consumption (no, yes). The physical examinations included measurement of blood pressure (BP); body height and weight; and circumferences of the waist, hips, and abdomen. Additionally, all participants took the fasting plasma glucose (FPG) and oral glucose tolerance test (OGTT), and blood samples were obtained to determine fasting glucose, total cholesterol (TC), triglycerides (TG), high-density lipoprotein cholesterol (HDL-C), and lowdensity lipoprotein cholesterol (LDL-C) levels.

\section{Definitions of DM and impaired glucose tolerance (IGT)}

DM was defined as a FPG level $\geq 7.0 \mathrm{mmol} / \mathrm{L}$, OGTT results of $\geq 11.11 \mathrm{mmol} / \mathrm{L}$, a self-reported history of DM, or current treatment with antidiabetic medication [32]. IGT was defined as 2-hour glucose levels of 7.8-11.1 $\mathrm{mmol} / \mathrm{L}(140-200 \mathrm{mg} / \mathrm{dL})$ on the 75-g OGTT [33].

\section{Dyslipidemia and hypertension}

Hypertension was defined as an average systolic blood pressure (BP) of $\geq 140 \mathrm{mmHg}$, an average diastolic $\mathrm{BP}$ of $\geq 90 \mathrm{mmHg}$, and/or self-reported current treatment for hypertension with antihypertensive medication [34].

Dyslipidemia was defined as self-reported current treatment with cholesterol-lowering medication or having one or more of the following levels: $\mathrm{TC} \geq 5.2 \mathrm{mmol} / \mathrm{L}$, $\mathrm{TG} \geq 1.7 \mathrm{mmol} / \mathrm{L}, \mathrm{HDL}-\mathrm{C}<1.04 \mathrm{mmol} / \mathrm{L}$, or LDL-C $\geq 3.4 \mathrm{mmol} / \mathrm{L}[35]$.

\section{Body mass index (BMI) and obesity definitions}

BMI was calculated as weight (in kilograms) divided by the square of height (in meters). According to standard criteria in Chinese adults, overweight and obesity were defined as BMIs of $24.0-27.9 \mathrm{~kg} / \mathrm{m}^{2}$ and $28.0 \mathrm{~kg} / \mathrm{m}^{2}$, respectively [36].

\section{Data collection}

Surveys were conducted in community health stations through face-to-face interviews, and physical examinations were performed by trained research staff guided by epidemiology professionals. A few participants completed the survey at home. A standardized questionnaire was administered in this survey.

\section{Statistical analysis}

Data are presented as means (standard deviations) for continuous variables (including age, BMI, TC, TG, HDL-C, LDL-C, and FPG), and as number (percentages) for categorical variables (including sex, age group, education level, annual family income, altitude group, residence group, and previous disease histories). The age-standardized prevalences of DM and IGT were calculated with the direct method using the world standard population [37] and are presented as rates with 95\% confidential intervals (CIs). Differences in continuous variables between two groups were compared using Student's $t$-test. Differences in categorical variables were compared using Pearson's chi-squared test for two groups and the linear-by-linear association for trends. Risk factors for DM and IGT were assessed by the chi-squared test and Student's $t$-test in the univariate analysis. A logistic regression analysis was performed to assess the risk factors for DM and IGT in the multivariate analysis, with the dependent variable set as DM or IGT (as dichotomous variables) and the independent variables set as factors determined to be statistically significant in the univariate analysis, respectively. The results of the multivariate analysis are presented as adjusted odds ratios (ORs) with 95\% confidence intervals (CIs) for the associated factors in the univariate analysis, respectively. Statistical significance was defined as a two-tailed $P<0.05$. SPSS version 15.0 for Windows (SPSS Inc., Chicago, IL, USA) was used for the analyses.

\section{Abbreviations}

DM: diabetes mellitus; IGT: impaired glucose tolerance; FPG: fasting plasma glucose; OR: odds ratio; CI: confidence interval; PHD2: prolyl hydroxylase 2; BMI: body mass index; BP: blood pressure; OGTT: oral glucose tolerance test; TC: total cholesterol; TG: triglycerides; HDL-C: high-density lipoprotein cholesterol; LDL-C: low-density lipoprotein cholesterol.

\section{Author contributions}

JW and XN contributed to the study design. SX, QW, BB, XFY, JL, and XDY performed data collection, and data interpretation. JW and XN performed data analysis. SX and QW contributed to drafting of the article. JW, XN, and QW performed critical review.

\section{ACKNOWLEDGMENTS}

We thank all participants of the local Tibetans, and local medical care professionals for their valuable contributions.

\section{CONFLICTS OF INTEREST}

None.

\section{FUNDING}

None. 


\section{REFERENCES}

1. Danaei G, Lu Y, Singh GM, Carnahan E, Stevens GA, Cowan MJ, Farzadfar F, Lin JK, Finucane MM, Rao M, Khang YH, Riley LM, Mozaffarian D, et al. Cardiovascular disease, chronic kidney disease, and DM mortality burden of cardiometabolic risk factors from 1980 to 2010: a comparative risk assessment. Lancet Diabetes Endocrinol. 2014; 2:634-47.

2. Zhou B, Lu Y, Hajifathalian K, Bentham J, Di Cesare M, Danaei G, Bixby H, Cowan MJ, Ali MK, Taddei C, Lo WC, Reis-Santos B, Stevens GA, et al. Worldwide trends in DM since 1980: a pooled analysis of 751 populationbased studies with 4.4 million participants. Lancet. 2016; 387:1513-30.

3. Bommer C, Heesemann E, Sagalova V, Manne-Goehler J, Atun R, Bärnighausen T, Vollmer S. The global economic burden of DM in adults aged 20-79: a cost-of-illiness study. Lancet Diabetes Endocrinol. 2017; 5:423-30.

4. Dagenais GR, Gerstein HC, Zhang X, McQueen M, Lear S, Lopez-Jaramillo P, Mohan V, Mony P, Gupta R, Kutty VR, Kumar R, Rahman O, Yusoff K,et al. Variations in DM Prevalence in Low-, Middle-, and High-Income Countries: Results from the Prospective Urban and Rural Epidemiology Study. Diabetes Care. 2016; 39:780-7.

5. Li YC, Liu XT, Hu N, Jiang Y, Zhao WH. Disease burden on DM in China, 2010. Zhonghua Liu Xing Bing Xue Za Zhi. 2013; 34:33-6.

6. Zhang N, Du SM, Ma GS. Current lifestyle factors that increase risk of T2DM in China. Eur J Clin Nutr. 2017; 71:832-8.

7. Yang W, Lu J, Weng J, Jia W, Ji L, Xiao J, Shan Z, Liu J, Tian H, Ji Q, Zhu D, Ge J, Lin L, et al. Prevalence of diabetes among men and women in China. N Engl J Med. 2010; 362:1090-101.

8. Wang L, Gao P, Zhang M, Huang Z, Zhang D, Deng Q, Li Y, Zhao Z, Qin X, Jin D, Zhou M, Tang X, Hu Y, et al. Prevalence and Ethnic Pattern of Diabetes and Prediabetes in China in 2013. JAMA. 2017;317:2515-23.

9. Li R, Lu W, Jiang QW, Li YY, Zhao GM, Shi L, Yang QD, Ruan Y, Jiang J, Zhang SN, Xu WH, Zhong WJ. Increasing prevalence of type 2 diabetes in Chinese adults in Shanghai. Diabetes Care. 2012; 35:1028-30.

10. Dong Y, Gao W, Nan H, Yu H, Li F, Duan W, Wang Y, Sun B, Qian R, Tuomilehto J, Qiao Q. Prevalence of type 2 diabetes in urban and rural Chinese populations in Qingdao. Diabet Med. 2005; 22:1427-33.

11. Li S, Guo S, He F, Zhang M, He J, Yan Y, Ding Y, Zhang J, Liu J, Guo H, Xu S, Ma R. Prevalence of Diabetes Mellitus and Impaired Fasting Glucose, Associated with Risk Factors in Rural Kazakh Adults in Xinjiang, China. Int J Environ Res Public Health. 2015; 12:554-65.

12. Castillo O, Woolcott OO, Gonzales E, Tello V, Tello L, Villarreal C, Méndez N, Damas L, Florentini E. Residents at high altitude show a lower glucose proile than sea-level residents throughout 12-hour blood continuous monitoring. High Alt Med Biol. 2007; 8:307-11.

13. Picon-Reategui E. Efect of chronic hypoxia on the action of insulin in carbohydrate metabolism. J Appl Physiol. 1966; 21:1177-80.

14. Calderón R, Llerena LA, Munive L, Kruger F. Intravenous glucose tolerance test in pregnancy in women living in chronic hypoxia. Diabetes. 1966; 15:130-2.

15. Krampl E, Kametas NA, Cacho Zegarra AM, Roden M, Nicolaides KH. Maternal plasma glucose at high altitude. BJOG. 2001; 108:254-7.

16. Lindgärde F, Ercilla MB, Correa LR, Ahrén B. Body adiposity, insulin, and leptin in subgroups of Peruvian Amerindians. High Alt Med Biol. 2004; 5:27-31.

17. Calderón R, Llerena LA. Carbohydrate metabolism in people living in chronic hypoxia. Diabetes. 1965; 14:100-5.

18. Woolcott OO, Castillo OA, Gutierrez C, Elashoff RM, Stefanovski D, Bergman RN. Inverse association between DM and altitude: a cross sectional study in the adult population of the United States. Obesity. 2014; 22:2080-90.

19. Ge RL, Simonson TS, Cooksey RC, Tanna U, Qin G, Huff CD, Witherspoon DJ, Xing J, Zhengzhong B, Prchal JT, Jorde LB, McClain DA. Metabolic insight into mechanism of high altitude adaptation in Tibetans. Mol Genet Metab. 2012; 106:244-7.

20. Lorenzo FR, Huff C, Myllymäki M, Olenchock B, Swierczek S, Tashi T, Gordeuk V, Wuren T, Ri-Li G, McClain DA, Khan TM, Koul PA, Guchhait P,et al. A genetic mechanism for Tibetan high altitude adaptation. Nat Genet. 2014; 46:951-6.

21. Tashi T, Feng T, Koul P, Amaru R, Hussey D, Lorenzo FR, RiLi G, Prchal JT. High altitude genetic adaptation in Tibetans: no role of increased hemoglobin-oxygen ainity. Blood Cells Mol Dis. 2014; 53:27-9.

22. Contreras AV, Torres N, Tovar AR. PPAR $\alpha$ a key nutritional $\&$ environmental sensor for metabolic adaptation. Adv Nutr. 2001; 4:439-52.

23. Ge RL, Simonson TS, Gordeuk V, Prchal JT, McClain DA. Metabolic aspects of high-altitude adaptation in Tibetans. Exp Physiol. 2015; 100:1247-55.

24. Bertoglia MP, Gormaz JG, Libuy M, Sanhueza D, Gajardo A, Srur A, Wallbaum M, Erazo M. The population impact of obesity, sedentary lifestyle, and tobacco and alcohol consumption on the prevalence of type 2 diabetes: Analysis of a health population survey in Chile, 2010. PLoS One. 2017; 12:e0178092.

25. Baliunas DO, Taylor BJ, Irving H, Roerecke M, Patra J, Mohapatra S, Rehm J. Alcohol as a risk factor for type 2 diabetes: a systematic review and meta-analysis. Diabetes Care. 2009; 32: 2123-32.

26. Shi L, Shu XO, Li H, Cai H, Liu Q, Zheng W, Xiang YB, Villegas R. Physical activity, smoking, and alcohol 
consumption in association with incidence of type 2 diabetes among middle-aged and elderly Chinese men. PLoS One. 2013; 8:e77919.

27. Nygren K, Hammarström A, Rolandsson O. Binge drinking and total alcohol consumption from 16 to 43 years of age are associated with elevated fasting plasma glucose in women: results from the northern Swedish cohort study. BMC Public Health. 2017; 17:509.

28. Prasad DS, Kabir Z, Dash AK, Das BC. Prevalence and risk factors for diabetes and impaired glucose tolerance in Asian Indians: a community survey from urban eastern India. Diabetes Metab Syndr. 2012; 6:96-101.

29. Snehalatha C, Ramchandran A, Kapur A, Vijay V. Agespecific prevalence and risk associations for impaired glucose tolerance in urban southern Indian population. J Assoc Physicians India. 2003; 51:766-9.

30. Guerrero-Romero F, Rodríguez-Moran M. Hypertriglyceridemia is associated with development of metabolic glucose disorders, irrespective of glucose and insulin levels: a 15-year follow-up study. Eur J Intern Med. 2014; 25:265-9.

31. Xu S, Jiayong Z, Li B, Zhu H, Chang H, Shi W, Gao Z, Ning X, Wang J. Prevalence and Clustering of Cardiovascular Disease Risk Factors among Tibetan Adults in China: A Population-Based Study. PLoS One. 2015; 10:e0129966.

32. Chinese DM Society. China Guideline for Type 2 DM. Beijing: Beijing University Medical Publication House; 2011.
33. Azami M, Nasirkandy MP, Mansouri A, Darvishi Z, Rahmati S, Abangah G, Dehghan HR, Borji M, Abbasalizadeh S. Global Prevalence of Helicobacter pylori Infection in Pregnant Women: A Systematic Review and Meta-analysis Study. International Journal of Women's Health and Reproduction Sciences. 2017; 5:30-6.

34. Chobanian AV, Bakris GL, Black HR, Cushman WC, Green LA, Izzo Joseph L. The seventh report of the Joint National Committee on Prevention, Detection, Evaluation, and Treatment of high blood pressure: The JNC 7 report. JAMA. 2003; 289:2560-72.

35. Joint Committee for Developing Chinese guidelines on Prevention and Treatment of Dyslipidemia in Adults. Chinese guidelines on prevention and treatment of dyslipidemia in adults. [Article in Chinese]. Zhonghua Xin Xue Guan Bing Za Zhi. 2007; 35:390-419.

36. Disease control, Ministry of Health of the People's Republic of China. The guidelines of Chinese adult overweight and obesity prevention and control. Beijing: People's Medical Publishing House. 2006.

37. Ahmad OB, Lopez AD, Murray CJ, Lozano R, Inoue M. Age standardization of rates: A new who world standard. Geneva: GPE Discussion Paper Series: No. 31; EIP/GPE/ EBD World Health Organization; 2001. Page 10. 